University of Nebraska - Lincoln

DigitalCommons@University of Nebraska - Lincoln

2003

Eight Gram-negative bacteria are 10,000 times more sensitive to cationic detergents than to anionic detergents

Soumitra Rajagopal

Nicole Eis

Kenneth Nickerson

Follow this and additional works at: https://digitalcommons.unl.edu/bioscinickerson

Part of the Environmental Microbiology and Microbial Ecology Commons, Other Life Sciences Commons, and the Pathogenic Microbiology Commons

This Article is brought to you for free and open access by the Papers in the Biological Sciences at DigitalCommons@University of Nebraska - Lincoln. It has been accepted for inclusion in Kenneth Nickerson Papers by an authorized administrator of DigitalCommons@University of Nebraska - Lincoln. 


\title{
Eight Gram-negative bacteria are 10,000 times more sensitive to cationic detergents than to anionic detergents
}

\author{
Soumitra Rajagopal, Nicole Eis, and Kenneth W. Nickerson \\ School of Biological Sciences, University of Nebraska, Lincoln, NE 68588-o666, U.S.A. \\ 1 Present address for S. Rajagopal: Department of Molecular Biology and Microbiology, \\ Tufts University School of Medicine, Boston, MA 02111, U.S.A. \\ 2 Present address for N. Eis: Signature Science, Inc., Austin, TX, U.S.A. \\ Corresponding author - K.W. Nickerson, email knickerson1@unl.edu
}

\begin{abstract}
In liquid culture, eight typical Gram-negative bacteria were ca. 10,000-fold more sensitive to cationic detergents than to the anionic detergent sodium dodecyl sulfate. Cetyltrimethylammonium bromide (CTAB) was inhibitory at concentrations ranging from $0.0006 \%$ to $0.01 \%$. Four pseudomonads able to form biofilms were ca. 1000-fold more resistant to CTAB on Luria-Bertani agar plates than they were in liquid culture. A lasI mutant of Pseudomonas aeruginosa was only able to tolerate $0.1 \%$ CTAB on Luria-Bertani agar plates but could tolerate $5 \%$ CTAB when supplemented with homoserine lactone containing culture supernatants.
\end{abstract}

Keywords: sodium dodecyl sulfate, cetyltrimethylammonium bromide, bacterial detergent resistance, homoserine lactones, Pseudomonas biofilms.

\section{Résumé}

En culture liquide, huit bactéries Gram négatif typiques étaient ca. 10,00o fois plus sensible aux détergents cationiques qu'au détergent anionique dodécyl sulfate de sodium. Le bromure de cétyltriméthylammonium (CTAB) était inhibiteur à des

Published in Can. J. Microbiol. 49: 775-779 (2003)

doi: 10.1139/Wo3-100

Copyright (C) 2003 NRC Canada. Used by permission.

Submitted 12 May 2003; revised 10 October 2003; accepted 23 October 2003; published 2

February 2004. 
concentrations allant de $0,0006 \%$ à $0,01 \%$. Quatre pseudomonades capables de former des biofilms étaient ca. 1000 fois plus résistant au CTAB sur des plaques de gélose Luria - Bertani qu'en culture liquide. Un mutant lasI de Pseudomonas aeruginosa ne pouvait tolérer que $0,1 \%$ de CTAB sur des plaques de gélose Luria-Bertani, mais pouvait tolérer $5 \%$ de CTAB lorsqu'il était complété par des surnageants de culture contenant de l'homosérine lactone.

Mots clés: sulfate de sodium dodécyle, bromure de cétyltriméthylammonium, résistance aux détergents bactériens, homosérine lactones, biofilms de Pseudomonas.

\section{Introduction}

Bacteria have developed specific responses to a great many chemical and environmental stresses (Storz and Hengge-Aronis 2000). Of these, we are interested in the chemical insults provided by detergents and have used sodium dodecyl sulfate (SDS) resistance as our model system (Nickerson and Aspedon 1992). Following our initial discovery that Enterobacter cloacae could grow in the presence of 25\% SDS (Kramer et al. 1980), we learned the following. (i) Bacteria tolerate SDS rather than metabolize or modify it (Kramer et al. 1980). (ii) SDS resistance is a common feature among the Enterobacteriaceae, in that 200 of 208 strains grew well in the presence of 5\% SDS (Kramer et al. 1984). (iii) SDS stress is accompanied by the synthesis of at least 19 unique or elevated SDS-induced proteins (Adamowicz et al. 1991). (iv) SDS resistance is energy dependent. The SDS-grown cells underwent rapid lysis when they ran out of energy or following the addition of sodium azide or dinitrophenol (Aspedon and Nickerson 1993). ( $v$ ) Part of this energy dependence appears to reside in the ClpAP and ClpXP energydependent intracellular proteases; $\operatorname{clp} P$ and $\operatorname{clp} B$ mutants of Escherichia coli were hypersensitive to SDS (Rajagopal et al. 2002). For wild-type $E$. coli, cellular ClpP levels, as determined by Western immunoblot analysis, increased ca. sixfold as the levels of added SDS increased from $0 \%$ to $2 \%$. As a summation of these studies, we concluded that the cellular response to SDS occurs in at least five different locations (capsule, outer membrane, periplasm, cytoplasmic membrane, and cytoplasm) and that SDS resistance is a cooperative effort by these five different compartments of the Gram-negative cell (Rajagopal et al. 2002). 
All the above studies examined the bacterial response to SDS, an anionic detergent. We next wanted to compare the cellular responses to cationic and anionic detergents. This subject had been broached in our survey of 208 strains of the Enterobacteriaceae (Kramer et al. 1984). None of the 200 SDS-resistant isolates could grow in the presence of $\geq 0.4 \%$ of three different cationic detergents. However, at that time we neglected to determine the actual threshold for sensitivity to cationic detergents, and accordingly, we have now reexamined that question. The present paper provides evidence that $(i)$ in liquid culture Gram-negative bacteria are ca. 10 ooo times more sensitive to cationic detergents than to anionic detergents, (ii) on solid media a few Pseudomonas spp. can tolerate high levels (3-5\%) of cationic detergents, and (iii) these Pseudomonas spp. appear to do so, in part, via rudimentary biofilm formation. Mutants of Pseudomonas aeruginosa that are defective in biofilm formation exhibit the same sensitivity to cationic detergents on solid media as in liquid media.

\section{Liquid culture}

Our previous work on cationic detergents (Kramer et al. 1984) showed that none of the 208 strains of the Enterobacteriaceae examined were able to grow in the presence of $\geq 0.4 \%$ tetradecyltrimethylammonium bromide. However, at that time we did not establish the lower limits for growth inhibition. This omission has now been corrected (Table 1). Typical representatives were chosen from the genera Serratia, Enterobacter, Escherichia, and Pseudomonas. All showed the high levels of tolerance for SDS expected for Gram-negative bacteria (Kramer et al. 1984); all were exquisitely sensitive to cationic detergents, such as cetyltrimethylammonium bromide (CTAB), benzalkonium chloride (BZAC), and cetylpyridinum chloride (CPC) (Table 1). Depending on the strain, the maximum levels of CTAB tolerated ranged from $0.0008 \%$ to $0.006 \%$ (Table 1). Thus, there was a difference of ca. 10 ooo-fold between the levels of cationic and anionic detergents tolerated by typical Gramnegative bacteria. Note that for $E$. coli the same threshold value for cationic CTAB was obtained with three commonly used strains of $E$. coli (Table 1) and for strain MC4100 grown at 25, 30, and $37^{\circ} \mathrm{C}$ (Table 1). This temperature independence makes it less likely that capsular colanic acid is 
Table 1. Maximum concentration of detergent that permits bacterial growth in Luria-Bertani broth.

\begin{tabular}{llllll} 
& & \multicolumn{3}{l}{ Detergent concn. ${ }^{a}$ (\%) } \\
\cline { 3 - 6 } Bacterium strain & Source & CTAB & BZAC & CPC & SDS \\
\hline Serratia marcescens 5384 & D.S. Katz & 0.005 & 0.002 & 0.0008 & $>10$ \\
Enterobacter cloacae VCK1 & This lab & 0.001 & 0.001 & 0.0004 & 25 \\
Escherichia coli MC4100 & S. Gottesman & $0.0008^{b}$ & 0.001 & 0.0004 & $>10$ \\
Pseudomonas aeruginosa & T.A. Kokjohn & 0.006 & 0.002 & 0.0008 & $>10$ \\
Pseudomonas aeruginosa lasl (PAO-JP1) & B.H. Iglewski & 0.008 & 0.002 & 0.0008 & $>5$ \\
Pseudomonas putida & J. Alfano & 0.006 & 0.002 & 0.0008 & $>10$ \\
Pseudomonas syringae & J. Alfano & 0.002 & 0.002 & 0.0006 & $>5$ \\
Pseudomonas fluorescens & Sippiwissett & 0.004 & 0.002 & 0.0006 & $>10$ \\
Pseudomonas chlororaphis & Sippiwissett & 0.006 & 0.002 & 0.0008 & $>10$ \\
\hline
\end{tabular}

a. Indicates the highest concentration of detergent at which growth occurred. The detergents used were cetyltrimethylammonium bromide (CTAB), benzalkonium chloride (BZAC), cetylpyridinium chloride (CPC), and sodium dodecyl sulfate (SDS). Multiple flasks contained Luria-Bertani broth supplemented with the indicated cationic detergent at concentrations ranging from $0.0001 \%$ up to $0.01 \%$. All flasks were shaken at $200 \mathrm{r} / \mathrm{min}$ at $37^{\circ} \mathrm{C}$ and growth was assessed after $24 \mathrm{~h}$. All experiments were repeated at least twice. CTAB is also known as hexadecyltrimethylammonium bromide.

b. The identical threshold value was obtained for E. coli MC4100 grown at 25,30 , and $37^{\circ} \mathrm{C}$ and for E. coli $\mathrm{C} 600$ and $\mathrm{DH} 5 \alpha$ grown at $37{ }^{\circ} \mathrm{C}$. The threshold for E. coli MC4100 grown at $42{ }^{\circ} \mathrm{C}$ was only $0.0001 \%$.

c. Isolated by S. Rajagopal on TSA plates with 3\% CTAB from mud samples obtained at Sippiwissett Bay, Mass., as part of the Microbial Diversity course, Marine Biology Lab, Woods Hole, Mass.

involved in any protection from the cationic detergents because the synthesis of colanic acid is turned on at temperatures $\leq 30{ }^{\circ} \mathrm{C}$ (Whitfield and Roberts 1999).

\section{CTAB selection plates}

Ten plates were prepared with trypticase soy agar supplemented with 3\% CTAB, streaked with three mud samples from Sippiwissett Bay, and incubated at $30^{\circ} \mathrm{C}$ for 3 days. Five mucoid colonies were obtained. All were oxidasepositive, Gram-negative rods that produced a pyocyanin-like pigment. Fatty acid analysis (Microbial ID, Inc., Newark, Del.) indicated that one colony was Pseudomonas chlororaphis, one was Pseudomonas fluorescens biotype A, and three were P. fluorescens biotype F. In liquid culture, all five Pseudomonas isolates were able to grow in the presence of $10 \%$ SDS, but even though they had been isolated by selection on $3 \% \mathrm{CTAB}$, they could not grow in liquid in the presence of even $0.01 \%$ CTAB. Two of the five Pseudomonas isolates 
were then chosen for more precise determination of the maximum levels of CTAB they could tolerate (Table 1). Interestingly, their threshold values for CTAB tolerated were equal to or less than those for our lab strains of $P$. aeruginosa and $P$. putida (Table 1).

\section{CTAB agar plates}

Bacteria such as P. fluorescens can produce confluent biofilms on solid nonmetabolizable agar surfaces (Belova et al. 1995). Based on the solid versus liquid differences exhibited by our five CTAB selected isolates, we decided to examine the rest of our cultures in this manner. Overnight cultures were inoculated on Luria-Bertani (LB) agar plates supplemented with various concentrations of CTAB (Table 2). None of the enteric bacteria grew at $>0.1 \%$ CTAB, whereas all Pseudomonas strains, except for $P$. syringae grew well on $5 \%$ CTAB-containing plates. Significantly, Pseudomonas syringae cannot form biofilms (Hirano and Upper 2000).

\section{Uronic acid estimation}

The extracellularpolysaccharide (EPS) matrix produced by Pseudomonas spp. is a complex biosynthetic polymer composed of poly-

Table 2. Maximum concentration of cetyltrimethylammonium bromide (CTAB) that permits bacterial growth on Luria-Bertani agar streak plates. ${ }^{a}$

\begin{tabular}{lccccccccc}
\multicolumn{10}{l}{ Concn. of CTAB in agar plates (\%) } \\
\cline { 2 - 8 } Bacterium & 5 & 4 & 3 & 1 & 0.5 & 0.1 & 0.05 & 0.01 \\
\hline Serratia marcescens & - & - & - & - & - & + & + & ++ \\
Enterobacter cloacae & - & - & - & - & - & - & + & ++ \\
Escherichia coli & - & - & - & - & - & - & - & ++ \\
Pseudomonas aeruginosa & + & + & ++ & ++ & ++ & +++ & +++ & +++ \\
Pseudomonas putida & + & + & + & ++ & ++ & ++ & +++ & +++ \\
Pseudomonas syringae & - & - & - & - & - & + & + & ++ \\
Pseudomonas fluorescens & & \pm & \pm & + & + & + & ++ & +++ & +++ \\
Pseudomonas chlororaphis & + & + & + & + & + & ++ & ++ & +++ \\
\hline
\end{tabular}

Note: +++ , confluent growth; ++ good growth; +, growth; \pm , minimal growth; -, no growth.

a. Plates were spot inoculated with $15 \mu \mathrm{L}$ of a saturated overnight culture of each organism in Luria-Bertani broth. The detergent-containing agar plates were incubated for 3 days at $30^{\circ} \mathrm{C}$.

b. Pseudomonas fluorescens biotype $\mathrm{F}$ was used for all the studies on $P$. fluorescens. 
saccharides, proteins, nucleic acids, and phospholipids (O'Toole and Kolter 1998; Stoodley et al. 2002). The amount of EPS produced by cells growing with increasing concentrations of CTAB was determined by the total carbohydrate and uronic acid contents. Uronic acid, which is a constituent of alginate EPS, was determined by the Asboe-Hansen method (Blumenkrantz and Asboe-Hansen 1973), total protein was estimated by the Bradford method (Bradford 1976), and total carbohydrate was determined by the phenol-sulfuric acid method (Hirs 1967). Pseudomonas aeruginosa PAO1 was inoculated in duplicate with $15 \mu \mathrm{L}$ of an overnight culture on the detergent-containing plates and incubated at $30{ }^{\circ} \mathrm{C}$ for 3 days. Cell growth was then scraped off the agar surface using $2 \mathrm{~mL}$ of sterile water (for protein estimation) or $2 \mathrm{~mL}$ of 100\% methanol (for uronic acid and carbohydrate determination) and the uronic acid - protein and the total carbohydrate-protein ratios were calculated. Compared with control cells grown on unsupplemented LB plates, the cultures grown with 5\% CTAB showed a twofold increase in uronic acid content and a 2.5-fold increase in total carbohydrates per milligram of total cell protein.

\section{Quorum sensing and biofilms}

The data presented in Table 2 suggest a correlation: those bacteria able to form biofilms on solid surfaces are able to grow on agar plates containing $\geq 1 \% \mathrm{CTAB}$, while those that cannot form biofilms cannot grow on $>0.1 \%$ CTAB. The importance of biofilms for cationic detergent resistance was supported by comparing wild-type $P$. aeruginosa PAO1 with the mutant lasI (PAO-JP1), which is defective in biofilm formation (Davies et al. 1998) because it is defective in the synthesis of the extracellular quorum-sensing molecule $N$-(3-oxododecanoyl)-Lhomoserine lactone $\left(3 \mathrm{OC}_{12}-\mathrm{HSL}\right)$. Pseudomonas aeruginosa $\mathrm{PAO} 1 \mathrm{re}-$ quires the lasI gene product $3 \mathrm{OC}_{12}$-HSL to develop a normal differentiated biofilm, and when the autoinducer $3 \mathrm{OC}_{12}-\mathrm{HSL}$ is added to the medium of growing lasI mutant bacteria, these cells develop biofilms that are indistinguishable from the wild-type organism (Davies et al. 1998). Thus, the lasI mutant is unable to produce $3 \mathrm{OC}_{12}-\mathrm{HSL}$ but can respond to it if it is provided exogenously in the medium. Significantly, wild-type $P$. aeruginosa PAO1, the parent of lasI, grew on LB agar with up to $5 \%$ CTAB, but the lasI mutant was only able to tolerate $0.1 \%$ CTAB on unsupplemented LB agar plates (Table 3). However, it too 
Table 3. Bacterial growth of wild type (PAO1) and las/ mutants (PAO-JP1) Pseudomonas aeruginosa PAO1 on Luria-Bertani (LB) agar plates with and without culture supernatant from $P$. aeruginosa PAO1.

\begin{tabular}{lccccc} 
& \multicolumn{2}{c}{ No supernatant ${ }^{a}$} & & \multicolumn{2}{c}{ With supernatant ${ }^{b}$} \\
\cline { 2 - 5 }$\%$ CTAB & Wild type & lasl mutant & & Wild type & lasl mutant \\
\hline 0.00 & +++ & ++ & +++ & +++ \\
0.01 & +++ & ++ & $\mathrm{ND}$ & $\mathrm{ND}$ \\
0.05 & +++ & + & +++ & +++ \\
0.10 & ++ & + & ++ & ++ \\
0.50 & ++ & - & $\mathrm{ND}$ & $\mathrm{ND}$ \\
1.00 & + & - & ++ & ++ \\
3.00 & + & - & ++ & $\mathrm{ND}$ \\
5.00 & \pm & - & ++ & ++ \\
\hline
\end{tabular}

Note: ND, not done; CTAB, cetyltrimethylammonium bromide. +++ , confluent growth; ++ , good growth; +, growth; \pm , minimal growth; - , no growth.

a. Overnight culture $(15 \mu \mathrm{L})$ was spot inoculated on LB agar plates with added cationic detergent of the appropriate concentration. All experiments were done in triplicate.

b. ell supernatants from a stationary phase culture of wild-type $P$. aeruginosa PAO1 were autoclaved and mixed in equal proportions with $2 \times$ strength LB. Agar ( $15 \mathrm{~g} / \mathrm{L})$ was added to the medium, followed by the cationic detergent of the appropriate concentration. Note that the longer chain homoserine lactones, such as those produced by $P$. aeruginosa and Vibrio fischeri, are well-known to be very heat stable (Eberhard 1972).

could tolerate $5 \%$ CTAB when supplemented with the culture supernatant containing heat stable (Eberhard 1972) $3 \mathrm{OC}_{12}-\mathrm{HSL}$ (Table 3). However, this extreme sensitivity of the lasI mutant was specific for the cationic detergents in that the mutant was still able to grow in the presence of $>5 \%$ SDS (Table 1). In this regard, it is important to note the distinction in methodology between our work and that of Davies et al. (1998). We were looking at the ability of bacteria to grow in the presence of SDS or CTAB, whereas their SDS sensitivity was based on the SDS-induced detachment of lasI mutant biofilm cells from a glass surface (Davies et al. 1998).

\section{Importance of biofilms}

We have shown that in liquid culture eight typical Gramnegative bacteria were ca. 10 ooo-fold more sensitive to cationic detergents than to anionic detergents (Table 1). Of these, the four pseudomonads able to form biofilms were ca. 1000-fold more resistant to CTAB on agar plates where they could form biofilms (Table 2) than they were in 
liquid culture. This value compares well with the factor of 1900 calculated by Grobe et al. (2002) for the greater resistance of $P$. aeruginosa in alginate beads to an alkyl dimethyl benzyl ammonium compound. In this regard, the inherent presence of some stationary-phase cells in an overnight inoculum is not sufficient for cationic detergent resistance. The importance of biofilms was amply illustrated by the inability of wild-type $P$. aeruginosa to tolerate CTAB in liquid culture (Table 1) or the lasI mutants of $P$. aeruginosa to tolerate CTAB on agar plates (Table 3). However, simply forming a capsule in planktonic cells was not sufficient for cationic detergent resistance. Enterobacter cloacae VCK1 was sensitive to low levels of CTAB (Table 1) even though it is a copious capsule producer; VCK1 colonies commonly form stalactites when plates are incubated upside down (Kramer et al. 1980). Similarly, synthesis of colanic acid by $E$. coli was turned on as the temperature is lowered to $30{ }^{\circ} \mathrm{C}$ (Whitfield and Roberts 1999) and yet the threshold value for CTAB sensitivity for $E$. coli was the same at 25, 30, and $37^{\circ} \mathrm{C}$ (Table 1).

Thus, CTAB resistance, unlike SDS resistance, is a characteristic of biofilm-forming cells rather than of capsule-forming planktonic cells. Admittedly, the physiological status of cells growing as a lawn on the surface of nutrient agar plates does not generate uniform or ideal biofilms. However, the rudimentary biofilms produced (Belova et al. 1995) did allow the four Pseudomonas spp. to grow at 1000-times higher concentrations of CTAB than they could in liquid culture. Thus, the involvement of biofilms in some fashion is indicated. This view is strengthened by the elegant work of Campanac et al. (2002) who used a circulating tygon loop method to show that biofilm formation was involved in the resistance of $P$. aeruginosa to quaternary ammonium compounds. Of course, the involvement of biofilms does not mean that cationic detergent resistance is an exclusive property of biofilms. Other mechanisms, such as the induction of efflux pumps, may be involved as well.

The hallmark of bacterial biofilms that segregates them from bacteria that are simply attached to a solid surface is that biofilms contain extracellular polymers that completely surround the bacterial cells (O'Toole and Kolter 1998; Stoodley et al. 2002). These extracellular polymers can be highly diverse in their chemical composition and may include substituted and unsubstituted polysaccharides, substituted and unsubstituted proteins, nucleic acids, and phospholipids 
(Stoodley et al. 2002). We do not yet know which aspect of biofilms is responsible for resistance to the cationic detergents. However, a recent study showed that mature biofilms of $P$. aeruginosa had radically different protein profiles from planktonic bacteria grown in chemostats; more than 800 proteins were shown to have a sixfold or greater change in expression level (Sauer et al. 2002). Thus, there are many possibilities to choose from regarding the actual biofilm-dependent mechanism for resistance to cationic detergents.

Acknowledgments - This research was supported by grants to K.W.N. from the Nebraska Corn Board and the National Science Foundation (MCB-0110999). We thank Barbara Iglewski for providing the $P$. aeruginosa lasI mutant and the Marine Biological Laboratory, Woods Hole, Mass., for the use of their facilities during the isolation of the detergent-resistant pseudomonads.

\section{References}

Adamowicz, M., Kelley, P.M., and Nickerson, K.W. 1991. Detergent (sodium dodecyl sulfate) shock proteins in Escherichia coli. J. Bacteriol. 173: 229-233.

Aspedon, A., and Nickerson, K.W. 1993. A two-part energy burden imposed by growth of Enterobacter cloacae and Escherichia coli in sodium dodecyl sulfate. Can. J. Microbiol. 39: 555-561.

Belova, S.E., Dorofeev, A.G., and Panikov, N.S. 1995. Kinetics and stoichiometry of growth of Pseudomonas fluorescens and Alcaligenes sp. on the surface of an agar medium. Mikrobiologiya, 64: 347-353.

Blumenkrantz, N., and Asboe-Hansen, G. 1973. New method for quantitative determination of uronic acids. Anal. Biochem. 54: 484-489.

Bradford, M.M. 1976. A rapid and sensitive method for the quantitation of microgram quantities of protein utilizing the principle of protein-dye binding. Anal. Biochem. 72: 248-254.

Campanac, C., Pineau, L., Payard, A., Baziard-Mouysset, G., and Roques, C. 2002. Interactions between biocide cationic agents and bacterial biofilms. Antimicrob. Agents Chemother. 46: 1469-1474.

Davies, D.G., Parsek, M.R., Pearson, J.P., Iglewski, B.H., Costerton, J.W., and Greenberg, E.P. 1998. The involvement of cell-to-cell signals in the development of a bacterial biofilm. Science (Washington, D.C.), 280: 295-298.

Eberhard, A. 1972. Inhibition and activation of bacterial luciferase synthesis. J. Bacteriol. 109: 1101-1105.

Grobe, K.J., Zahller, J., and Stewart, P.S. 2002. Role of dose concentration in biocide efficacy against Pseudomonas aeruginosa biofilms. J. Ind. Microbiol. Biotechnol. 29: 10-15. 
Hirano, S.S., and Upper, C.D. 200o. Bacteria in the leaf ecosystem with emphasis on Pseudomonas syringae - a pathogen, ice nucleus and epiphyte. Microbiol. Mol. Biol. Rev. 64: 634-653. Hirs, C.H.W. 1967. Glycopeptides. Methods Enzymol. 11: 411-413.

Kramer, V.C., Calabrese, D.M., and Nickerson, K.W. 1980. Growth of Enterobacter cloacae in the presence of $25 \%$ sodium dodecyl sulfate. Appl. Environ. Microbiol. 40: 973-976.

Kramer, V.C., Nickerson, K.W., Hamlett, N.V., and O'Hara, C. 1984. Prevalence of extreme detergent resistance among the Enterobacteriaceae. Can. J. Microbiol. 30: $711-713$.

Nickerson, K.W., and Aspedon, A. 1992. Detergent-shock response in enteric bacteria. Mol. Microbiol. 6: 957-961.

O'Toole, G.A., and Kolter, R. 1998. Initiation of biofilm formation in Pseudomonas fluorescens WCS365 proceeds via multiple, convergent signalling pathways: a genetic analysis. Mol. Microbiol. 28: 449-461.

Rajagopal, S., Sudarsan, N., and Nickerson, K.W. 2002. Sodium dodecyl sulfate hypersensitivity of $\operatorname{clpP}$ and $\operatorname{clpB}$ mutants of Escherichia coli. Appl. Environ. Microbiol. 68: 4117-4121.

Sauer, K., Camper, A.K., Ehlrich, G.D., Costerton, J.W., and Davies, D.G. 2002. Pseudomonas aeruginosa displays multiple phenotypes during development as a biofilm. J. Bacteriol. 184: 1140-1154.

Stoodley, P., Sauer, K., Davies, D.G., and Costerton, J.W. 2002. Biofilms as complex differentiated communities. Annu. Rev. Microbiol. 56: 187-209.

Storz, G., and Hengge-Aronis, R. 2000. Bacterial stress responses. American Society of Microbiology (ASM), Washington, D.C.

Whitfield, C., and Roberts, I.S. 1999. Structure, assembly, and regulation of expression of capsules in Escherichia coli. Mol. Microbiol. 31: 1307-1319. 